\title{
Effect of Antioxidant activity of Astaxanthin in improving Human Spermatozoa lipid Peroxidation
}

\author{
Dian Nurmawati ${ }^{1^{*}}$, Aucky Hinting ${ }^{2}$ and Sudjarwo ${ }^{3}$ \\ ${ }^{1}$ PT Kimia Farma Apotek's ; JL. Budi Utomo 1, Jakarta Pusat, Indonesia \\ ${ }^{2}$ Department of Medical Biology, Faculty of Medicine, Airlangga University, Surabaya, Indonesia \\ ${ }^{3}$ Department of Pharmaceutical Chemistry, Faculty of Pharmacy, Airlangga University, Surabaya, Indonesia
}

\begin{abstract}
Malondialdehyde (MDA) is the final product of lipid peroxidation which reacts with Thiobarbituric Acid (TBA) to produce red color and can be observed by spectrophotometry at a wavelength of $532 \mathrm{~nm}$. Astaxanthin is an antioxidant that can reduce MDA by counteracting free radicals in lipid peroxidation in human spermatozoa. The objective of this study was to identify the antioxidant activity of astaxanthin in improving human spermatozoa lipid peroxidation, with parameters of color, odor, $p H$, volume, viscosity, concentration, morphology, motility and MDA levels. In this study, astaxanthin was given to 19 patients orally in a single dose of $8 \mathrm{mg}$ per day for 30 days. As a negative control, six people were given with CMC Na placebo. MDA level measurement was performed using a spectrophotometer and the quality of spermatozoa was measured using WHO 2010 parameters. Significant difference in MDA level was found before and after astxanthin administration with a p-value of 0.022 $(p<0.05)$ and significant difference in sperm motility was also found with a $p$-value 0.000 ( $p<0.01)$, spermatozoa morphology with $p 0.021$ ( $p<0.05)$, and concentration with $p 0.001$ ( $p<0.05)$. There was no significant difference before and after astaxanthin administration in sperm viscosity with $p 0.414$ ( $p>0.05)$, volume with $p 0.965$ ( $p>0.05)$ and $p H$ with $p 0.401$ ( $p>0.05)$. In conclusion, astaxanthin can reduce lipid peroxidation, improve morphology, increase concentration and motility of human spermatozoa.
\end{abstract}

Keywords: Astaxanthin, lipid peroxidation, MDA, Human spermatozoa, Male infertility.

\section{INTRODUCTION}

The prevalence of infertility throughout the world has increased over time and has reached around $15 \%[1,2]$, the contribution of male factors to infertility by $36.8 \%$ [3] and causes in idiopathic men by $31.7 \%$ [4]. Oxidative stress (OS) causes $30 \%-80 \%$ of cases of infertility in males by reducing spermatozoa motility and suppressing fertility potential $[5,6,7]$. OS occurs because of the imbalance due to excessive production of reactive oxygen species (ROS) so that it is unable to be neutralized by antioxidants in the spermatozoa cytoplasm [8] resulting in oxidative damage to membrane lipid, protein, and DNA [9]

Spermatozoa cell membrane contains large amounts of polyunsaturated fatty acids which are very easily oxidized by ROS. Free radicals will cause lipid peroxidation which will be formed in a longer chain. As a result, membrane permeability increases, and spermatozoa membrane integrity decreases [10,11], 2011), cellular enzymes become inactive, and then the DNA structures will be damaged and and cell apoptosis will occur. As a result, the activity and number of sperm cells decreases, its motility decreases, producing sperm with abnormal morphology, and finally causes infertility [8]. The motility of spermatozoa is a factor that has a significant effect and is a major cause of infertility $[12,13,14]$.

The measurement of the level of lipid peroxidation is performed by measuring the final product, the malondialdehyde (MDA), a dialdehyde compound as the end product of non-saturated fatty acid oxidation which is toxic to cell membranes [15]. Measurement of MDA levels is an indirect measurement of free radical activity as an indicator of oxidative stress which can be carried out by Thiobarbituric Acid Reactive Substances (TBARS test) with visible spectrophotometer methods [16]. In cases of idiopathic infertility it is recommended to perform ROS testing, one of which is by determining the MDA level [17]. 
This lipid peroxidation can be prevented by fat-soluble antioxidants [18]. The negative effects of ROS on these cell membranes can be reduced by antioxidants. Astaxanthin is a fat-soluble antioxidant that functions as a radical scavenger so that it can prevent the initiation stage and contains peroxyl radicals so that it can prevent the propagation stage [19]. Astaxanthin is an antioxidant that has an effectiveness of 500-1000 times better than vitamin $\mathrm{E}$ in preventing fat peroxidation in vivo, 6000 times than vitamin C, 800 times than Coenzyme Q10, 560 times than green tea extract, and 75 times than lipoic acid [20]. Astaxanthin (3,3'dihydroxy-4,4'-diketo-beta, beta'-carotene) has a radical group which has a strong activity of neutralizing free radicals and provides protection against lipid peroxidation and oxidation damage by cell membranes and tissues and has an anti-inflammatory effect by inhibiting cytokines $[21,22,23]$.

\section{MATERIALS AND METHODS}

\subsection{Materials}

Distilled water (Brataco), Astaxanthin caplets $4 \mathrm{mg}, 0.5 \%$ Eosin B in distilled water (Merck), 10\% Negrosin solution in distilled water (Merck), 20\% trikoloacetic acid, 1\% Na Thiobarbiturate and MDA solution, HCl $1 \mathrm{~N}$. The astaxanthin was in the form of 4 mg caplets derived from Haematococus pluvialis green algae produced by PT. X Jakarta. CMC Na $30 \mathrm{mg}$ which is put in capsules was used as placebo.

\subsection{Instruments}

Glass (Pyrex), Elliason pipette, centrifuge (Eppendorf 5403), multi-channel pipette (BioRad, USA), hemocytometer (Perkin Elmer 9800), pH meter (Eutech), votex (Maxi Mix II type 37,600), phase contrast microscope (Nikon), centrifuge (Eppendorf 5403), water bath, and HP 8452A Diode Array Spectrophotometer.

\subsection{Sample}

This was an experimental study. Samples were obtained from one hospital in Surabaya after obtaining approval from the Health Research Ethics Committee, Dr. Soetomo Hospital, Surabaya, Indonesia with Ethical Clearance No. 710/Panke.KKE/XII/2016.

Subjects of this study were 25 persons, consisting of 19 persons in the sample group who were given with 8 mg astaxanthin per day in a single dose for 30 days and six persons in the placebo group who were given with CMC-Na 30 mg every day for 30 days. Everyone has signed informed consent about the treatment or examination that will be carried out after receiving enough information and approved without coercion by the concerned.

Sample of the study was sperm from subjects with primary or secondary infertility who came routinely for examination and had signed informed consent or statement of agreement regarding the treatment or examination that they will carry out after obtaining sufficient information and approved without coercion by the person concerned.

\subsection{Sampling}

Preceded by a period of sexual abstinence (no discharge of sperm fluid in any way) for 3-5 days, sperm retrieval was carried out in a separate room which was done by masturbation, and ejaculated into a wide-mouth sterile container. All ejaculate was stored and the temperature was maintained between $20^{\circ}-40^{\circ} \mathrm{C}[24]$.

\subsection{Sperm quality analysis}

According to WHO 2010, it includes color, odor, pH, volume, viscosity, concentration, morphology and motility at the time before and after administration of the astaxanthin or placebo.

\subsection{Procedure for determining MDA levels}

A total of $0.5 \mathrm{~mL}$ was added with $1.0 \mathrm{~mL}$ of $30 \%$ TCA, and centrifuged at $2500 \mathrm{rpm}$ for 5 minutes. The supernatant was pipetted as much as $0.7 \mathrm{~mL}$, added with $200 \mu \mathrm{l}$ of $1 \% \mathrm{Na}$ Thiobarbiturate, then added with $\mathrm{HCl} 1 \mathrm{~N}$ up to $10.0 \mathrm{ml}$, then incubated for 135 minutes on the water bath. The absorption was observed by spectrophotometer method in a wavelength of $532 \mathrm{~nm}$ [5].

\subsection{The making of MDA standard solutions}

MDA $(50.4 \mathrm{mg})$ was mixed with distilled water to $100.0 \mathrm{~mL}(504.0 \mu \mathrm{g} / \mathrm{mL})$, pipetted as much as $1.0 \mathrm{ml}$, dissolved with distilled water to $10.0 \mathrm{~mL}(50.4 \mu \mathrm{g} / \mathrm{mL})$. MDA $(50.4 \mu \mathrm{g} / \mathrm{mL})$ was pipetted as much as $6 ; 10 ; 12 ; 20 ; 30 ; 50 ; 70$ and $125 \mu \mathrm{L}$, then added with $1.0 \mathrm{~mL}$ of $30 \%$ TCA and $200 \mu \mathrm{L}$ of $1 \% \mathrm{Na}$ Thiobarbiturate. The incubation was performed for 135 minutes on a water bath and its absorption was observed with spectrophotometer at a wavelength of $532 \mathrm{~nm} \mathrm{[5].}$ 
International Journal of Advances in Scientific Research and Engineering (ijasre), Vol 5 (10), October-2019

\section{RESULTS AND DISCUSSION}

\subsection{Sample characteristics}

Of 25 persons, primary infertility was found in $72 \%$ and secondary infertility was in the remains. The average length of marriage was 3.93 \pm 4.7000 years, the number of children owned was $0.41 \pm 0.7703$ children, the average age was $25.48 \pm 6.6651$ years, under 40 years so they were not in the age of Advanced Paternal Age (APA) which has a significant impact on infertility [25]. The demographic profile of the sample characteristics is shown in Table 1.

Table 1. The sample characteristics

\begin{tabular}{ll}
\hline Biodata & \multicolumn{1}{c}{ Values } \\
\hline Age & $25.48 \pm 6.6651$ years old \\
Occupation: & $12(48 \%)$ persons \\
$-\quad$ Entrepreneur & $6(24 \%)$ persons \\
$-\quad$ Online driver & $5(20 \%)$ persons \\
$-\quad$ Government employee & $2(8 \%)$ persons \\
$-\quad$ No formal job & $3.93 \pm 4.7000$ years \\
Length of marriafe & $0.41 \pm 0.7703$ children \\
Number of children & \\
Invertility status & $18(72 \%)$ persons \\
$-\quad$ Primary invertility & $7(28 \%)$ persons \\
$-\quad$ Secondari invertility &
\end{tabular}

\subsection{Color and odor of spermatozoa}

The color and the odor $\mathrm{w}$ as normal at the time of, before, or after the administration of placebo and astaxanthin. The color of the sperm was grayish white, a distinctive odor of sperm like chlorine due to by sperm oxidation, an aliphatic polyamine that is produced by the prostate gland [26, 27].

\subsection{Spermatozoa pH}

In this study, the $\mathrm{pH}$ was in the normal range, which was 7.2-7.8. There was no significant differences in either group, both before and after the administration of placebo and astaxanthin. Similar results were reported in studies conducted in the US [28], Norway [29], and Pakistan [30,31].

\subsection{Volume}

In placebo group, the average volume before was $1.88 \pm 0.373 \mathrm{~mL}$ and after was $2.65 \pm 0.725 \mathrm{~mL}$. There was no significant difference before and after the administration of CMC-Na ( $>0.05)$. In sample group, the average volume before was $2.58 \pm 1.094$ $\mathrm{mL}$ and after $2.97 \pm 2.056 \mathrm{~mL}$. There was no significant difference before and after astaxanthin administration ( $>>0.05)$. A retrospective study in Brazil showed that sperm volume was the only parameter that decreased with age [32]. Volume of spermatozoa before and after treatment in placebo and sample is shown in figure 1.

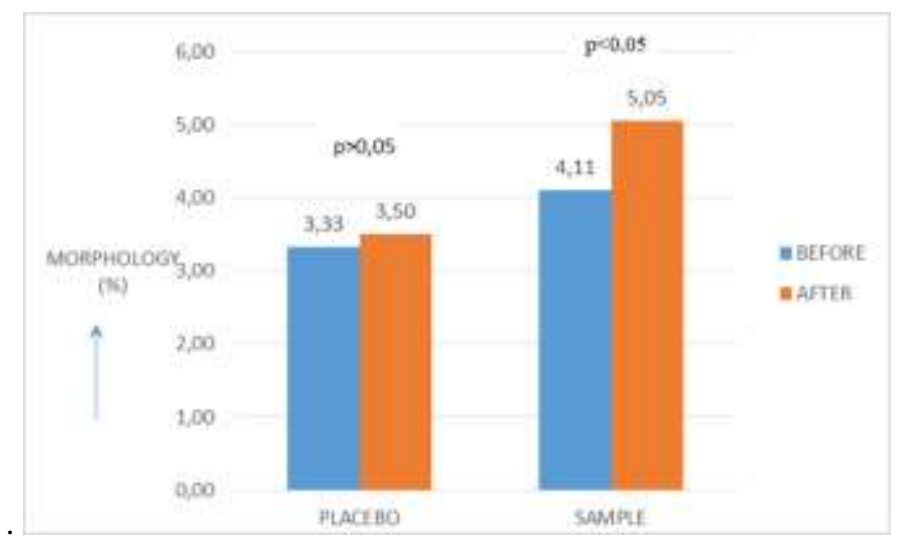

Figure 1. Volume of spermatozoa before and after treatment in placebo and sample.

\subsection{Viscosity}

In placebo group, the average viscosity before and after treatment was $2.00 \pm 0 \mathrm{~cm}$. There were no significant differences before and after the administration of CMC-Na ( $>>0.05)$. In sample group, the average viscosity before treatment was $2.26 \pm 0.733 \mathrm{~cm}$ and 
after treatment $2.16 \pm 0.375 \mathrm{~cm}$. There were no significant differences before and after astaxanthin administration $(\mathrm{p}>0.05)$. Viscosity was negatively correlated with motility with a correlation coefficient value of -0.045 ( $>>0.05)$. Spermatozoa viscosity before and after treatment in placebo and samples is shown in figure 2.

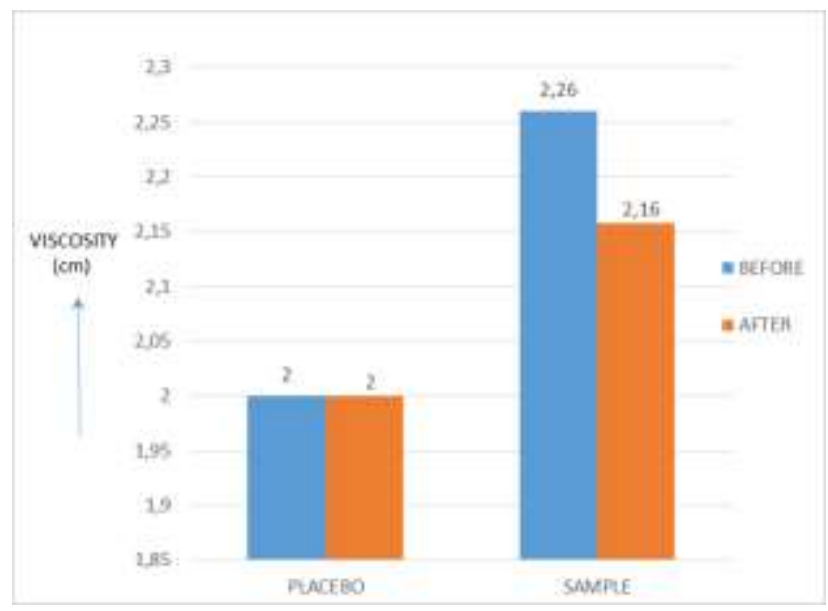

Figure 2. Spermatozoa viscosity before and after treatment in placebo and samples

\subsection{Concentration}

In placebo group, the average concentration before treatment was $67.33 \pm 52.015 \times 10^{6} / \mathrm{mL}$ and after treatment $56.48 \pm 52.472 \times$ $10^{6} / \mathrm{mL}$. There were no significant difference before and after the administration of CMC-Na ( $>0.05$ ). In sample group, the average volume before treatment was $34.29 \pm 22.383 \times 10^{6} / \mathrm{mL}$ and after treatment $41.84 \pm 18.610 \times 10^{6} / \mathrm{mL}$. There were significant differences before and after Astaxanthin administration ( $>0.05)$. The concentration correlates with motility, and the correlation coefficient value was $0.003(\mathrm{p}<0.05)$.

Normal sperm concentration was 15 million sperm/mL or more [24]. The number or concentration of sperm in this study showed an increase but not significant. This was because there was no strict control to prevent disruption of spermatogenesis process that affects spermatozoa concentration, such as diet, smoking, alcohol, lifestyle, or the surrounding environment [33, 34].

Analysis of spermatozoa concentration showed a significant difference between before and after Astaxanthin administration. The lower the concentration of spermatozoa, the more infertile a man is, but rarely is there a man who does not produce sperm at all. This decrease in sperm concentration can be caused by disruption of spermatogenetic process due to, for example, high testicular temperature or smoking [27, 35]. ]. Spermatozoa concentration of before and after treatment in placebo \& sample is shown in figure 3.

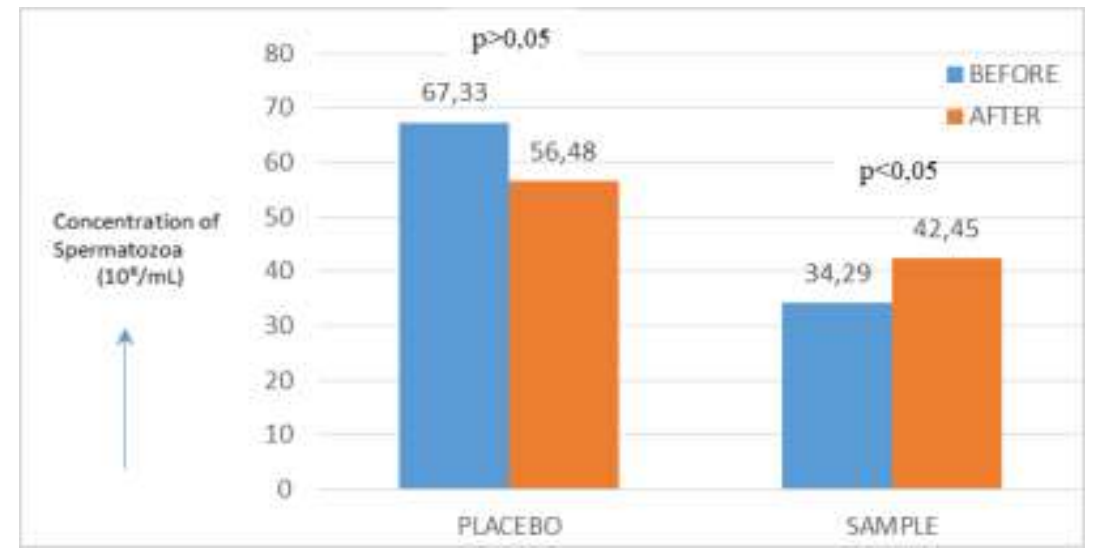

Figure 3. Spermatozoa concentration of before and after treatment in placebo \& sample

\subsection{Morphology}

In placebo group, the average morphology before treatment was $3.33 \pm 1.225 \%$ and after treatment $3.5 \pm 1.378 \%$. There were no significant differences before and after the administration of $\mathrm{CMC}-\mathrm{Na}(\mathrm{p}>0.05)$. In the sample group, the average morphology was 
4.11 \pm 1.560 and after treatment 5.05 $\pm 1.779 \%$. There were significant differences before and after Astaxanthin administration ( $p>0.05)$. Morphology correlates with motility with a correlation coefficient value of $0.000(\mathrm{p}<0.05)$.

The morphological changes in spermatozoa are affected by testicular function. The more normal the head, the better the function of the testes. Changes in the shape of the head and tail occur in the testes during spermatogenesis process. Nicotine endangers the process of spermatogenesis because it increases the production of cholesterol, triglycerides, phospholipids, free fatty acids in testicles and peroxidative damage $[34,36]$.

Changes in the shape of spermatozoa head affect sperm maturity, which also affects theotility and viability [27, 37]. There is a correlation between the normal morphology and pregnancy rates in vivo and in vitro [38].

Astaxanthin has a long structure that can increase stiffness and mechanical strength to protect the body from oxidation on cell membranes and it is hydrophilic and lipophilic so that it can more effectively inhibit reactive oxygen species against lipid peroxidation $[20,39,40]$, so that it can improve the morphology of spermatozoa. Spermatozoa morphology before and after treatment in placebo \& sample is shown in figure 4.

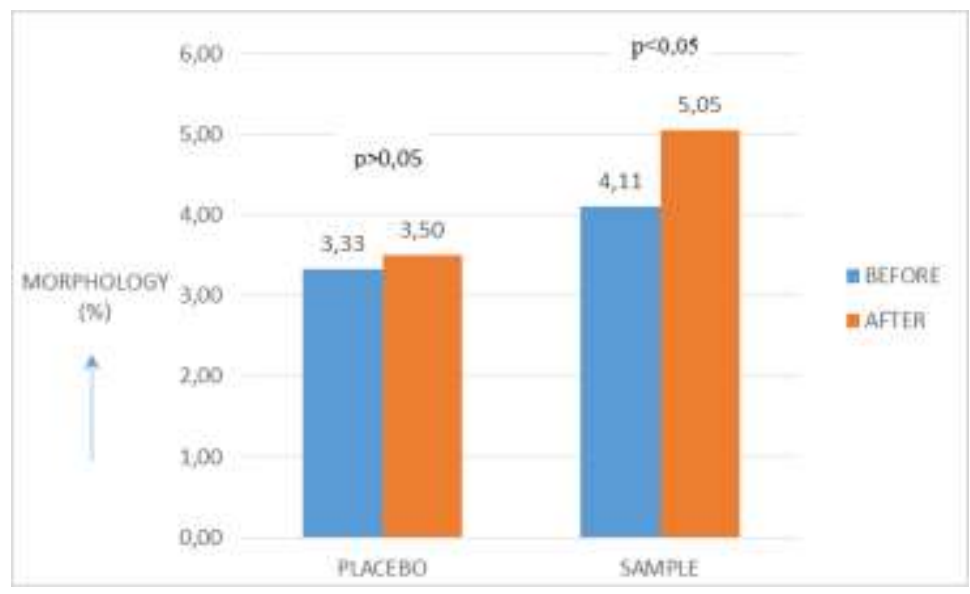

Figure 4. Spermatozoa morphology before and after treatment in placebo \& sample

\subsection{Malondialdehyde (MDA)}

In placebo group, the average concentration of MDA spermatozoa before treatment was $2.1 \pm 2.379 \mathrm{nmol} / 10^{6} / \mathrm{mL}$ and after treatment $1.65 \pm 1.537 \mathrm{nmol} / 10^{6} / \mathrm{mL}$. There were no significant differences before and after CMC-Na administration with a $\mathrm{p}$ value 0.345 ( $p>0.05)$. In the sample group, the average concentration of MDA before treatment was $1.74 \pm 1.146 \mathrm{nmol} / 10^{6} / \mathrm{mL}$ and after treatment $1.27 \pm 0.672 \mathrm{nmol} / 10^{6} / \mathrm{mL}$. There were significant differences before and after Astaxanthin administration with p 0.022 ( $p>0.05$ ). In total group (placebo and sample) there were significant differences before and after treatment with $\mathrm{p} 0.009$ $(\mathrm{p}<0.01)$. The MDA had negative correlation with motility with a correlation coefficient of 0.006 ( $<<0.05)$. ). Spermatozoa MDA before and after treatment in placebo and samples is shown in figure 5. 


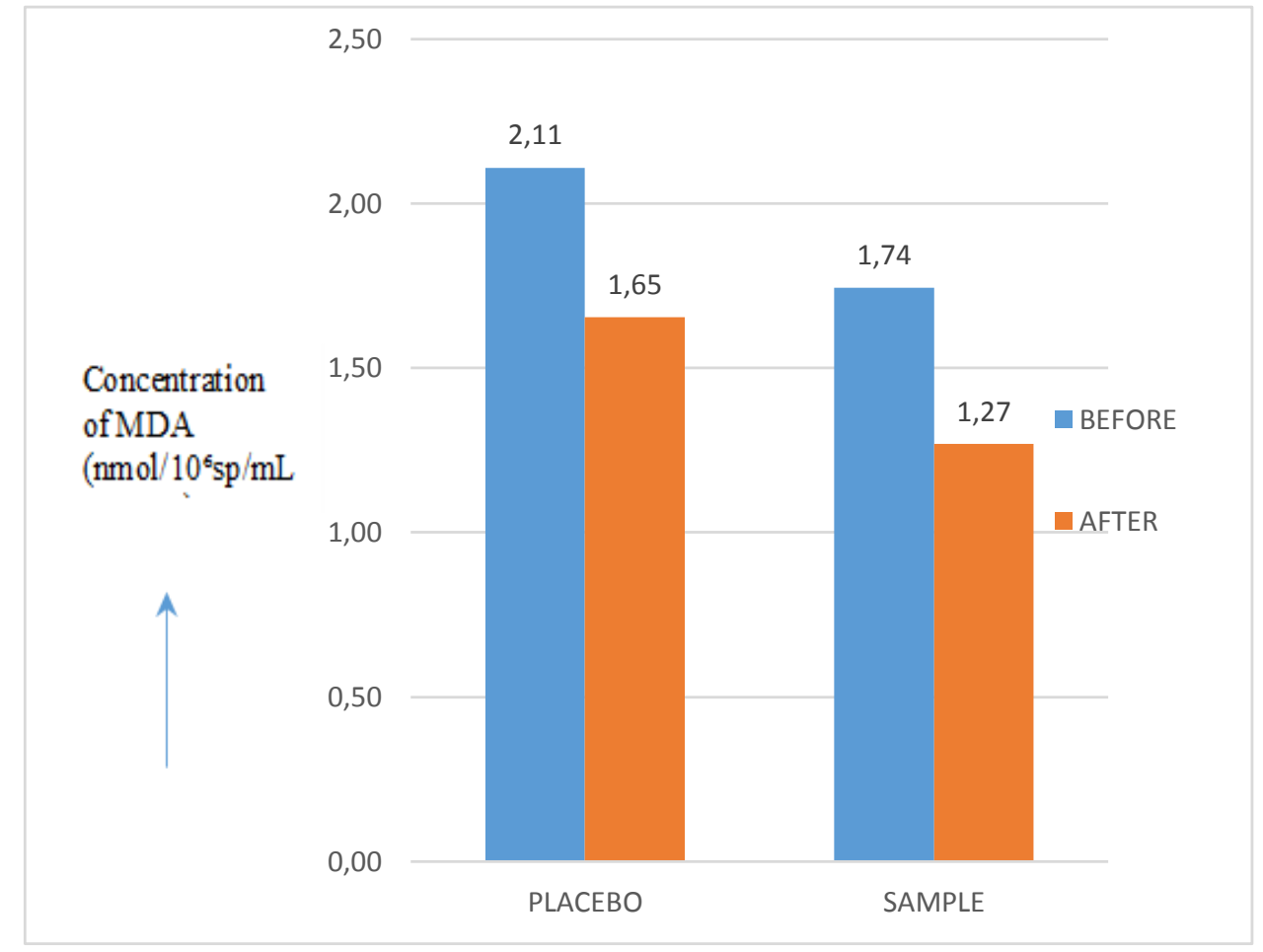

Figure 5. Spermatozoa MDA before and after treatment in placebo and samples

Receiver Operating Characteristic (ROC) analysis on MDA factor revealed AUC (Area Under Curve) value of 0.662 which was higher than 0.5. The cut-off value for the MDA factor was less than 1.98 with a sensitivity value of $100 \%$ and a specificity of $35.3 \%$. This showed that if the MDA value is $<1.98$, the prediction of the motility level normality $(>40)$ will be $100 \%$. If the MDA value is $>1.98$, the prediction of the motility level will be included in abnormal category $(<40)$ which is $35.5 \%$. Figure 6 shows the results of ROC analysis on the MDA factor. MDA cut-off values (nmol/10 ${ }^{6}$ Spermatozoa/ml) on spermatozoa motility is shown in figure 6.

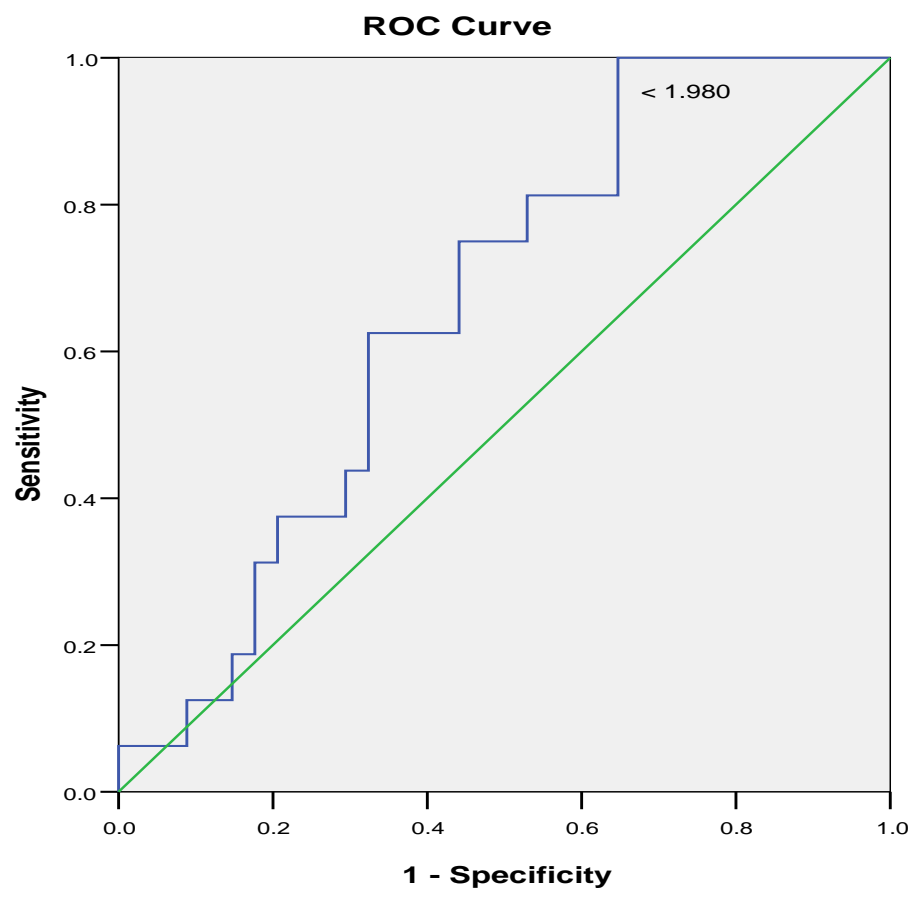

Figure 6. MDA cut-off values $\left(\mathrm{nmol}^{1} \mathbf{1 0}^{6} \mathrm{Sp} / \mathrm{ml}\right)$ on spermatozoa motility

Spermatozoa have polyunsaturated fatty acids in the plasma membrane that are useful for membrane fluidity and membrane fusion such as acrosome reactions and spermatozoa-ovum interactions, but it causes spermatozoa to be very susceptible to free radical attack and lipid peroxidation [34] (Alahmar, 2019). Lipid peroxidation is a key mediator of ROS-induced sperm damage 
that causes infertility. The end result of lipid peroxidation is the breakdown of unsaturated fatty acid chains and MDA production $[34,41]$.

Sperm MDA level is negatively correlated with spermatozoa membrane integrity because high levels of MDA will reduce cell membrane integrity and increase spermatozoa damage resulting in a decrease in sperm quality. So, the higher the MDA level, the lower the percentage of normal integrity of spermatozoa membrane. As a result, the activity and number of sperm cells decreases, produces sperm with abnormal morphology, decreases motility, decreases sperm tail movement and interaction between spermovum membranes in the fertilization process fails $[8,32,41,42]$. In the cases of idiopathic infertility it is recommended to carry out ROS examination, one of which is by determining the MDA level [17].

Malonaldehyde analysis is an indirect analysis of free radicals and is a fairly easy analysis to determine the amount of free radicals formed. Direct analysis of free radicals is very difficult to do, because radical compounds are very unstable, electrophile and the reaction takes place so quickly that the measurement is very difficult when it is in the form of free radical compounds [43].

This lipid peroxidation can be prevented by fat-soluble antioxidants. Astaxanthin is a fat soluble antioxidant that functions as a radical scavenger so that it can prevent the initiation stage and it has peroxyl radicals so that it can prevent the propagation stage $[7,18,19]$. Like tocopherols, astaxanthin will transfer hydrogen atoms with single electrons to capture peroxyl lipids, thus preventing lipid peroxidation. Astaxanthin is a carotenoid group that is a chain breaking antioxidant because, during a peroxidation chain reaction, pyroxyl and alkoxyl radicals will be cut to prevent the propagation stage to produce antioxidant radicals that are not reactive $[41,44]$.

Astaxanthin is a pure antioxidant that can maintain the structure of the bilayer membrane by reducing $40 \%$ lipid hydroperoxide $(\mathrm{LOOH})$, while non-polar carotenoids, such as lycopene and beta-carotene, show a strong pro-oxidant effect which increasing $85 \% \mathrm{LOOH}$. Therefore, astaxanthin is needed in cases of male infertility because it can maintain cell membrane integrity, regulation of spermatogenesis and spermatozoa motility [45,46,47,48].

Astaxanthin has a unique molecular structure that allows it to work inside and outside the cell membrane. This provides better protection than beta-carotene and vitamin $\mathrm{C}$ which can be positioned inside the lipid bilayer. This serves as a protection against oxidative damage by various mechanisms, such as singlet oxygen cooling; radical scavenging to prevent chain reactions; preservation of membrane structure by inhibiting lipid peroxidation, and improvement of immune system function and regulation of gene expression. As reported by various authors, astaxanthin inhibits lipid peroxidation in biological samples [21,34,41,49,50].

\subsection{Motility}

In placebo group, the average motility before treatment was $24.17 \pm 11.143 \%$ and after treatment $28.33 \pm 6.831 \%$. There were no significant differences before and after $\mathrm{CMC}-\mathrm{Na}$ administration $(\mathrm{p}>0.05)$. In sample group, the average motility before treatment was 23.42 \pm 11.187 and after treatment 39.74 $\pm 4.556 \%$. There were significant differences before and after Astaxanthin administration $(\mathrm{p}<0.05)$. Motility of spermatozoa before and after treatment on placebo and samples is shown in figure 7

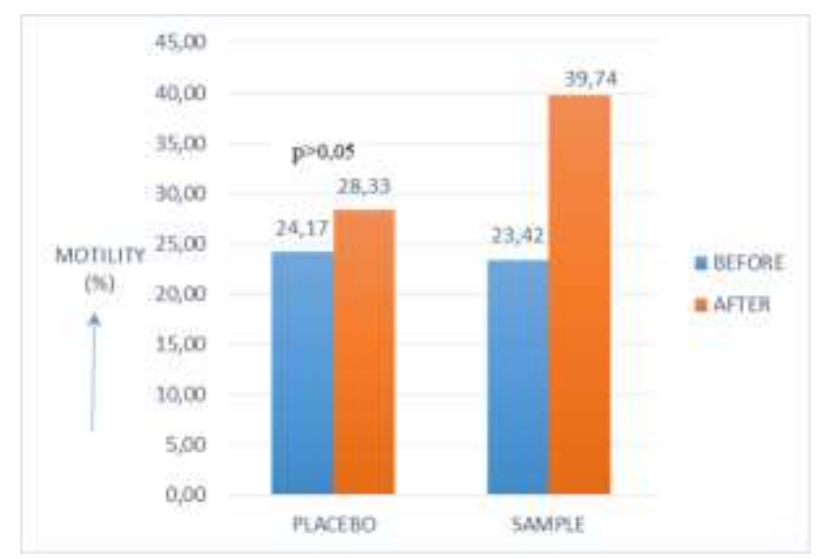

Figure 7. Motility of spermatozoa before and after treatment on placebo and samples 
Spermatozoa motility requires energy, the ATP, which is mostly produced in the midpiece of the mitochondrial flagellum via the OXPHOS pathway [51,52]. During the OXPHOS process, 1-2\% of oxygen consumed is released as reactive oxygen species (ROS), which can damage spermatozoa [53,54].

The decrease in spermatozoa motility is partly due to high ROS production, which is not able to be neutralized by the antioxidant defense system in spermatozoa or sperm plasma [9,55]. Spermatozoa plasma membrane is rich in unsaturated fatty acids, but has few antioxidant enzymes in the cytoplasma so they are very susceptible to oxidative damage, so membrane permeability increases and spermatozoa membrane integrity becomes low [11,2]. Disruption of membrane structure and function produces malondialdehyde compounds (MDA) which have a significant contribution to male infertility [2]. If motility is low, the migration of spermatozoa is not achieved, so the fertilization process does not occur, resulting in an infertile state. The Parameters of semen quality in the placebo and treatment groups is shown in Table 2.

Table 2. Parameters of semen quality in the placebo and treatment groups

\begin{tabular}{|c|c|c|c|c|c|c|}
\hline \multirow[t]{2}{*}{ Parameter } & \multicolumn{3}{|c|}{ Placebo group } & \multicolumn{3}{|c|}{ Treatment group } \\
\hline & Before & After & $\begin{array}{c}\text { Comparability } \\
\text { test }(\alpha 0,05)\end{array}$ & Before & After & $\begin{array}{c}\text { Comparability } \\
\text { test }(\alpha 0,05)\end{array}$ \\
\hline Color & Normal & Normal & - & Normal & Normal & - \\
\hline Odor & Normal & Normal & - & Normal & Normal & - \\
\hline $\mathrm{pH}$ & $7,2-7,8$ & $7,2-7,8$ & - & $7,2-7,8$ & $7,2-7,8$ & - \\
\hline Volume (mL) & $\begin{array}{l}1.88 \pm \\
0.373\end{array}$ & $\begin{array}{l}2.65 \pm \\
0.725\end{array}$ & $\mathrm{p}>0,05$ & $\begin{array}{l}2.58 \pm \\
1.094\end{array}$ & $2.97 \pm 2.056$ & $\mathrm{p}>0,05$ \\
\hline Viscosity $(\mathrm{cm})$ & $2.00 \pm 0.00$ & $2.00 \pm 0.00$ & $\mathrm{p}>0,05$ & $\begin{array}{l}2.26 \pm \\
0.733\end{array}$ & $2.16 \pm 0.375$ & $p>0,05$ \\
\hline $\begin{array}{l}\text { Concentration } \\
\left(\times 10^{6} / \mathrm{mL}\right)\end{array}$ & $\begin{array}{l}67.33 \pm \\
52.015\end{array}$ & $\begin{array}{l}56.48 \pm \\
52.472\end{array}$ & $p>0,05$ & $\begin{array}{l}34.29 \pm \\
22.383\end{array}$ & $\begin{array}{c}41.84 \pm \\
18.610\end{array}$ & $\mathrm{P}<0,05$ \\
\hline Morphology (\%) & $\begin{array}{l}3.33 \pm \\
1.225\end{array}$ & $3.5 \pm 1.378$ & $\mathrm{p}>0,05$ & $\begin{array}{c}4.11 \pm \\
1,560\end{array}$ & $5.05 \pm 1.779$ & $\mathrm{p}<0,05$ \\
\hline Motility (\%) & $\begin{array}{c}24.17 \pm \\
11.143 \\
\end{array}$ & $\begin{array}{c}28.33 \pm \\
6.831 \\
\end{array}$ & $\mathrm{p}>0,05$ & $\begin{array}{c}23.42 \pm \\
11.187 \\
\end{array}$ & $\begin{array}{c}39.74 \pm \\
4.556 \\
\end{array}$ & $\mathrm{p}<0,05$ \\
\hline
\end{tabular}

Antioxidant therapy is needed because seminal antioxidant level is unable to compensate for increased ROS production [56]. Astaxanthin is a natural carotenioid group needed to maintain cell membrane integrity and regulation of spermatogenesis that affects sperm motility and results in male infertility [46,57]. The effect of astaxanthin manifests through several mechanisms, such as electron scavenger through conjugated double bonds, and inhibition of lipid peroxidation. Recent research on the antioxidant activity of astaxanthin suggests that intraperitoneal injection of astaxanthin can increase sperm motility, amount, and viability, by reducing lipid peroxidation and increasing antioxidant defense [58].

Motility and MDA have a negative correlation with the correlation coefficient value of -0.356 and $p$ value 0.006 ( $p<0.05$ ). High MDA levels can result in decreased sperm motility [5]. High MDA level is influenced by lipid peroxidation level, which indirectly indicates high number of free radicals [15], which increases membrane permeability, cellular enzyme inactivation, damage to DNA structure and cell apoptosis, which results in decreased motility [8].

\section{CONCLUSION}

Astaxanthin in a single dose of $8 \mathrm{mg}$ per day consumed for 30 days reduce lipid peroxidation and improve the concentration, morphology and motility of spermatozoa, so it can improve the function of human spermatozoa.

\section{ACKNOWLEDGMENT}

The authors would like to thank to all subjects those who have involved in this research.

\section{CONFLICT OF INTERESTS}

The authors declare that they have no conflict of interests in publication of this article.

\section{REFERENCES}

[1]. Kumalic Imamovic S, Pinter B, 2014. Review of clinical trials on effects of oral antioxidants on basic semen and other parameters in idiopathic oligoasthenoteratozoospermia. Biomed Res Int; 426951. 
[2]. Agarwal A, Ahmad G, Sharma R, 2015. Reference values of reactive oxygen species in seminal ejaculates using chemiluminescence assay. J Assist Reprod Genet, 32: 1721-9.

[3]. Razzak, A.H. \& Wais, S.A. (2002). The infertile couple: a cohort study in Duhok, Iraq. EMHJ - Eastern Mediterranean Health Journal, 8 (2-3), 234-238, 2002 https://apps. who.int/iris/handle/10665/119155

[4]. Dohle, Colpi, Hargreave, Papp, Jungwirth, Weidner, The EAU Working Group on Infertility. EAU Guidelines on Male Infertility. European Urology 48 (2005) 703-711

[5]. Sudjarwo, Hinting A, Sudoyo H, Marzuki S., 2001. Analysis of Asian mtDNA haplogroups in low and normal sperm motility. Proceeding of the VIIth International Congress Andrology. Medimond Inc. 53.

[6]. Nallella; K.P., Rakesh, K. Sharma., Shyam S. R. Allamaneni, Ashok Agarwal, 2005. Identification of male factor infertility using a novel semen quality score and reactive oxygen species levels. Center for Advanced Research in Human Reproduction, Infertility, and Sexual Function, Glickman Urological Institute and Department of Obstetrics-Gynecology, Cleveland Clinic Foundation - Cleveland, Ohio.

[7]. Shukla Govind, Nagalakshmi Yaparthy, Jyothika Vanamali, C.J. Sampath Kumar. Astaxanthin capsules: An excellent choice to improve sperm parameter and fertility. Medico Research Chronicles, 2016; 3(5): 328-332.

[8]. Jedrzejowska RW., Wolski JK., Hilczer JS., 2013. The role of oxidative stress and antioxidants in male fertility. Cent European J Urol. Vol.66., No. 1, pp: 60-67.

[9]. Zelen Ivankaa, Mitrovi Marinaa, Juriši-Škevin Aleksandrab, Arsenijevi Slobodanc, 2010. Activity of superoxide dismuthase and catalase and content of Malondialdehyde in seminal plasma.

[10]. Sikka, S.C., 2004. Role of Oxidative Stress and antioxidant in andrology and asisted reproductive technology. J. Androl. Vol. 25, pp. 5-18.

[11]. Sharma R, Garu U (2011) Effects of lead toxicity on developing testes in Swiss mice. Univ J Environ Res Technol 1:390398Google Scholar

[12] Aitken RJ. Free radicals, lipid peroxidation and sperm function. Reprod Fertil Dev. 1995; 7: 659-668.

[13]. Wael, S., Watuguly, T.W. \& Winarto. 2014. Pemberian Minyak Jintan Hitam (NigellaSativa) Terhadap Motilitas dan Jumlah Spermatozoa Tikus Sprague Dawley yang Dipapar Minuman Tradisional Arak Ambon (Sopi). Molucca Medica 4(2), pp.132-36.

[14]. Wagner H, Cheng JW, Ko EY. Role of reactive oxygen species in male infertility, 2018. Arab J Urol, 16: 35-43.

[15]. Halliwell, B., and Gutteridge, J. M. C., 2007. Free Radicals in Biology and Medicine. New York : Oxford University Press. pp. 619-633.

[16]. Clarkson, M.Priscilla and Thompson, S.Heather., 2000. Antioxidants; what role do the play in physical activity and health. The American Journal of Clinical Nutrition. No. 72 (suppl.), pp. 637S - 646S.

[17]. Mayorga-Torres BJ, Camargo M, Cadavid ÁP, du Plessis SS, Cardona Maya WD. Are oxidative stress markers associated with unexplained male infertility? Andrologia. 2017; 49(5)

[18]. Sadek Kadry Mohamed, 2012. Antioxidant and Immunostimulant Effect of Carica Papaya Linn. Aqueous Extract in Acrylamide Intoxicated Rats. Acta Inform Med 20(3): 180-185.

[19]. Middleton, Angela M. Patterson, Lucy Gardner, Caroline Schmutz and Brian A. Ashton. Leukocyte extravasation: chemokine transport and presentation by the endothelium. Blood 2002; 100: 3853-3860.

[20]. Wood, V and Yamashita, E. 2009. Antioxidant Symposium 2009: An Update on Clinical Research, Jakarta. Available at: http://blog.perriconemd.com/astaxanthin-side-effects. Accessed 1 September 2016. 
[21]. Goto, S., Kogure, K., Abe, K., Kitahama, K., Yamasitha, E., Terada, H., 2001. Efficient Radical Trapping at Surface and Inside The Phospholipid Membrane is Responsible for Highly Potent Antiperoxidative Activity of The Carotenoid Astaxanthin. Biochim. Biophys Acta. Vol. 1512, No. 2., pp. 251-258.

[22]. Suseela, M.R., Toppo, K. 2006. Haemotococcus pluvialis-a Green Algae, Richest Natural Source of Astaxanthin. Current Science.Vol 90, No.12, pp. 1602-1603.

[23]. Vincent, W. 2007. Terapi dan Pencegahan Penyakit dengan Astaxanthin. Jurnal Simposia Vol.6, No.12.

[24]. World Health Organization. 2010. WHO Laboratory Manual for Examination of Human Semen and Sperm-Cervical Mucus Interaction, Five Edition. Cambridge University Press, New York.

[25]. Brandt Justin S, Mayra A. Cruz Ithier, Todd Rosen, Elena Ashkinadze, 2018. Review Advanced paternal age, infertility, and reproductive risks: A review of the literature. Wiley Prenatal Diagnosis. DOI: 10.1002/pd.5402.

[26].Khaidir, M., 2006. Penilaian Tingkat Fertilitas dan Penatalaksanaanya pada pria.www. jurnalkesmas.com/index.php/kesmas/article/view/20/15. Diakses tanggal 16 Agustus 2016.

[27]. Jagtap Richa, Mariah Banker, Ritu Hinduja, Snesha Sathe and Sulba Arora, 2019. Infertility and Assisted Reproductive Technology. Jaypee Brothers Medical Publisher.

[28]. Harraway, Nathan G. Berger, Norman H. Dubin, 2000. Semen pH in patients with normal versus abnormal sperm characteristics. American Journal of Obstetrics and Gynecology. Volume 182, Issue 5, pp. 1045-1047.

[29]. Haugen TB, Grotmol T, 1998. pH of Human Semen. International Journal of Andrology 21(2):105-108.

[30]. Khan Ikhlas A, Abourashed Ehab A, 2011. Leung's Encyclopedia of Common Natural Ingredients used in Food, Drugs, and Cosmetics, Third Edition. Published by John Wiley \& Sons.

[31]. Ramzan MH, Ramzan M, Ramzan F, Ramzan M, Ramzan MA, Shah M, 2015. Insight into the serum kisspeptin levels in infertile males. Archives of Iranian Medicine 18(1): 12-17.

[32]. Cavalcante M.B., Rochma M.P., Dias M.L.C.M, Dias O.J.O, Souza D.O.A., Roberto I.G. 2008. Interferência da idade sobre a qualidade seminal Rev. Bras. Ginecol. Obstet. 30: 561-565.

[33]. Tremellen K, 2008. Oxidative stress and male infertility- a clinical perspective. Human Reproduction Update. Vol. 14, No. 3, pp. 243-258.

[34]. Alahmar AT, 2019. Role Of Oxidative Stress in Male infertility: An Updated Review. J Human Reprod Sci. Jan-Mar; 12(1);4-18. doi: 10.4103/jhrs.JHRS_150_18.

[35]. Cooper, T.G., 2010. WHO reference values for human semen characteristics. Hum. Reprod. Update. 16(5), p. 559.

[36]. Kim KH, Joo KJ, Park HJ, Kwon CH, Jang MH, Kim CJ, 2005. Nicotine induces apoptosis in TM3 mouse Leydig cells. Fertility and sterility, 83(4): 1093-1099.

[37]. Schill, Wolf-Bernhard et al., 2006. Andrology for the Clinician. Springer. p. 41.

[38]. Agustinus, Reny I’tshom, MPB Dyah Pramesti, 2018. Biologi Reproduksi Pria. Airlangga University Press, hal. 88.

[39]. Capelli, Bob and Cysewski, Gerald; 2018. Natural Astaxanthin: King of carotenoids (natural astaxanthin concentrate in Haemotococcus microalgae. Cyanotech corporation, Cyanotech University.

[40]. Zini A, San Gabriel M, Baazeem A. Antioxidants and sperm DNA damage: A clinical perspective. J Assist Reprod Genet. 2009; 26: 427-32. 
[41]. Trilaksani W. 2003. Antioksidan:jenis, sumber, mekanisme kerja dan peran Terhadap Kesehatan. TermPaper Introductory Science Philosophy (PPS702). Institut Pertanian Bogor.

[42].Sanocka D., Kurpisz M. 2004. Reactive oxygen species and sperm cells. Reproductive Biology and Endocrin41, ology, 2: $12-18$.

[43]. Cicerol, A.F.G. and Derosa, G. 2005. Rice bran and its main components: potential role in the management of coronary risk factors.Hypocholesterolemic effect of diet supplemented with indian bean(Dolichos lablab L. var Lignosus) seeds.

[44]. Mc-Nulty, HP., Byun, J., Lockwood, SF., Jacob, RF., Mason, RP., 2007. Differential effects of carotenoids on lipid peroxidation due to membrane interactions: X-ray diffraction analysis. Biochim Biophys Acta. Vol. 176; pp. 167-174.

[45]. Hogarth CA, Griswold MD, 2010. The key role of Vitamin A in spermatogenesis. J Clin Invest, 120: 956-62.

[46]. Ursoniu Sorin, Amirhossein Sahebkar, Maria-Corina Serbain, Macie Banach. Lipid profile and glucose changes after supplementation with astaxanthin: a systematic review and meta-analysis of randomized controlled trials. Arch Med Sci , 2015; 11, 2: 253-266.

[47]. Lazzarino Giocomo, Listorti H, Bilottta G, Capozzolo T, Amorini AM, Longo S, Caruso G, Lazzarino G, Tavazzi B and Bilotta P. Water and Fat-Soluble Antioxidants in Human Seminal Plasma and Serum of Fertile Males. Antioxidants $2019 ;$; 96.

[48]. Kamath, B.S.; Srikanta, B.M.; Dharmesh, S.M.; Sarada, R.; Ravishankar, G.A, 2008. Ulcer preventive and antioxidative properties of astaxanthin from Haematococcus pluvialis. Eur. J. Pharmacol., 590, 387-395. [Google Scholar] [CrossRef (Kamath, et al., 2008).

[49]. Rao Ranga, A.; Sarada, R.; Baskaran, V.; Ravishankar, G.A. Identification of carotenoids from green alga Haematococcus pluvialis by HPLC and LC-MS (APCI) and their antioxidant properties. J. Microbiol. Biotechnol. 2009, 19, 1333-1341. [Google Scholar] (Rao, et al., 2009).

[50]. May Panloup P, Chretien MF, Savagner F, Vasseur C, Jean M, Malthiery Y, Reynier P. 2003. Increased sperm mitochondrial DNA content in male infertility. Hum Reprod. Vol 18, No. 3, pp. 550- 556..

[51]. Koppers, A.J., De Iuliis, G.N., Finnie, J.M., McLaughlin, E.A., Aitken, R.J. Significance of mitochondrial reactive oxygen species in the generation of oxidative stress in spermatozoa. J. Clin. Endocrinol. Metab. 2008; 93: 3199-3207.

[52]. Du Plessis, S.S.; Agarwal, A.; Mohanty, G.; van der Linde, M. Oxidative phosphorylation versus glycolysis: What fuel do spermatozoa use? Asian J. Androl. 2015; 17: 230-235.

[53]. Wagner H, Cheng JW, Ko EY. Role of reactive oxygen species in male infertility, 2018. Arab J urol, 16: 35-43.

[54]. Bui AD, R. Sharma, R. Henkel and A Agarwal, 2018. Reactive oxygen species impact on Sperm DNA and its role In male infertility. Andrologia, 2018, 50: 13012.

[55]. Hidalgo DM, Maria Julia Bragado, Ana R. Batista, Pedro F. Oliviera and Marco G. Males, 2019. Antioxidants and Male Infertiliy: From Molecular Studies to Clinical Evidence. Antioxidants, 2019. 8: 89.

[56]. Ashrafizadeh Milad, Ahmadi Zahra, 2019. Effect of Astaxanthin treatment on the Sperm Quality of the Mice Treated with Nicotine. Rev Clin Med vol. 6. No. 1.

[57]. Kishimoto Y, Yoshida H, Kondo K. Potential anti-atherosclerotic properties of astaxanthin. Mar Drugs. 2016 ;14. pii:E35.

[58]. Zhou XY, Zhang F, Hu XT, et al. Depression can be prevented by astaxanthin through inhibition of hippocampal inflammation in diabetic mice. Brain Res. 2017; 1657: 262-268. 